\title{
Goal Orientation and Academic Performance in Adult Distance Education
}
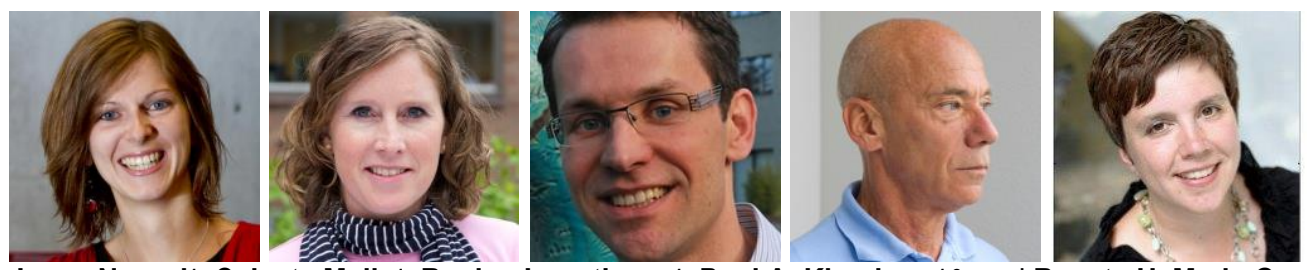

Joyce Neroni' ${ }^{1}$, Celeste Meijs' ${ }^{1}$, Ruslan Leontjevas ${ }^{1}$, Paul A. Kirschner ${ }^{1,2}$, and Renate H. M. de Groot' ${ }^{1,3}$ 1Open University of the Netherlands, Heerlen, The Netherlands, 2University of Oulu, Oulu, Finland, ${ }^{3}$ Maastricht University, Maastricht, the Netherlands

\begin{abstract}
Research has shown the importance of goal orientation in predicting academic performance for children, adolescents, and college students in traditional educational settings. Studies on this relationship within adult distance education, however, are lacking. To fill this gap, the present study was conducted to investigate the relationship between goal orientation and academic performance in adult distance learners. A sample of $N=1128$ distance university students (age 18-75 years) filled out an online questionnaire. Their exam grades were collected from the files of the Open University of the Netherlands (OUNL). A mixed model regression showed performance approach goal orientation to be a positive predictor of academic performance, whereas performance avoidance and work avoidance were negative predictors of academic performance. Non-significant results were found for mastery approach as well as for mastery avoidance. Implications of these results are discussed.
\end{abstract}

Keywords: ALOUD study, adult distance students, achievement goal questionnaire, AGQ, work avoidance, mixed model analysis 


\section{Introduction}

Being academically successful is highly dependent on what motivates a person to study, something which can also be expressed as someone's goal orientation (Dweck, 1986). Although the relationship between goal orientation and academic achievement has been studied extensively in traditional educational settings for children (e.g., Anderman \& Midgley, 1997; Butler, 2008), adolescents (e.g., Brdar, Rijavec, \& Loncaric, 2006; Greene, Miller, Crowson, Duke, \& Akey, 2004; Steinmayr, Bipp, \& Spinath, 2011; Steinmayr \& Spinath, 2009), and college students (e.g., Elliot, Murayama, \& Pekrun, 2011; Harackiewicz, Durik, Barron, Linnenbrink-Garcia, \& Tauer, 2008; Pekrun, Elliot, \& Maier, 2009), not much is known about this relationship for adult learners in distance education. As society and technologies are rapidly changing and the amount of information continues to increase at exponential rates (Nagy, Farmer, Bui, \& Trancik, 2013) it has become increasingly important for people to keep up with these developments throughout their lives. Therefore, the group of adult learners is rapidly gaining both in size and importance. In a time-limited environment, distance education is a suitable educational alternative. Hence, the present study was conducted to investigate the relationship between goal orientation and academic performance in adults participating in distance education.

\section{Distance Education}

In our continuously changing society, employers often demand that employees continue to develop their professional knowledge and skills throughout their careers. As a result, formal adult education is growing in importance. In 2015, 10.7\% adults in Europe between 25 and 64 years of age participated in formal education or training (Eurostat, 2016). Time to study is often limited, however, as many people have a full time job, a family, and/or a busy social life. Distance education can be a suitable solution because, generally speaking, this type of education allows people to study from their own home and according to their own time schedule.

Over the years, many definitions of distance education have been presented. A widely-accepted definition is the one of Schlosser and Simonson (2010), who defined distance education as "institution-based, formal education where the learning group is separated, and where interactive telecommunications systems are used to connect learners, resources, and instructors” (p. 1). This definition consists of four elements. The first element is that distance education is institution-based, which separates it from self-study. Second, the definition states that the learning group is separated. Teachers and students could either be separated by time (i.e., asynchronous distance education), place (i.e., separate locations), or intellect. The third part of the definition concerns the use of interactive telecommunication systems. Interaction between teacher and students, as well as between students and their fellow students, can either be at the same time (i.e., synchronous) or at different times (i.e., asynchronous). Telecommunication includes communication by electronic (e.g., the Internet) as well as non-electronic media (e.g., the postal system). The last element, connecting learners, resources, and instructors, refers to the interaction between teachers and students, with available resources that promote learning (e.g., assignments, (virtual) classes, or course material). All four elements can be found in the educational system of the Open University of the Netherlands (OUNL): students study in their own time and pace (i.e., asynchronous) and, most of the time, from their own homes (i.e., separation by place), they communicate for the most part by the Internet, and interaction between teachers and students, as well as between students and their fellow students, takes place synchronous (e.g., virtual classes, exams) as well as asynchronous (e.g., assignments, e-mail contact) in time. Therefore, in the present study, the definition of Schlosser and Simonson (2010) was utilized. 
A common problem in all higher education, but especially in distance education, is the high dropout and low retention rate (Berge \& Huang, 2004; Yukselturk, Ozekes, \& Türel, 2014). Knowing what motivates students to follow courses in distance education in the first place, and knowing the relationship between their goal to study and academic performance might be valuable information to heighten the retention rate for adult distance learners.

\section{Achievement Goal Theory}

People can have different motives to reach a certain goal, also known as one's goal orientation (Dweck, 1986). To understand the concept of goal orientation, it is important to refer to the achievement goal theory by Dweck (1986) and Nicholls (1984). They stated that goal orientation can be classified in mastery and performance goal orientation. In educational context, this means that students who are mastery oriented focus on developing knowledge and skills, whereas students who are performance oriented focus on doing better than others (Dweck, 1986; Nicholls, 1984). In 1996, Elliot and Harackiewicz made a distinction within the performance orientation. They argued that people could either focus on doing better than others (i.e., performance approach) or on avoiding doing worse than others (i.e., performance avoidance). Similarly, Elliot and McGregor (2001) argued that an approach-avoidance distinction could be made for mastery goals, with mastery approach defined as people focusing on developing knowledge and skills, and mastery avoidance defined as people focusing on avoiding stagnating in development or losing skills. More recently, a fifth concept was added to the goal orientation construct (Harackiewicz et al., 2008), a stance in which people are striving for success using as little effort as possible and are, thus, classified as having a work avoidance orientation.

\section{Goal Orientation and Academic Performance}

The relationship between goal orientation and academic performance has been studied extensively (for examples of review studies and meta-analyses, see Cellar et al., 2011; DeShon \& Gillespie, 2005; Huang, 2012; Payne, Youngcourt, \& Beaubien, 2007). Traditionally, researchers found a strong positive relationship between mastery goal orientation and academic outcomes, while performance goal orientation was often found to be weakly negatively to non-significantly related to academic outcomes (for meta-analysis, see Huang, 2012). The distinction between approach and avoidance within the performance goal orientation clarified these findings, namely, that the performance avoidance goal orientation was negatively related to learning outcomes, whereas the performance approach goal orientation was positively related to learning outcomes (Cellar et al., 2011; Chen, 2015; Diseth, 2011; Elliot \& Church, 1997; Elliot \& McGregor, 2001; Huang, 2012). Since Elliot and McGregor (2001) introduced their 2 x 2 framework with mastery also subdivided into approach and avoidance, the positive relationship between mastery goal orientation and academic achievement seemed to disappear. Most researchers failed to find a significant relationship between mastery approach and academic achievement (Abd-El-Fattah \& Patrick, 2011; Cury, Elliot, Da Fonseca, \& Moller, 2006; Elliot \& McGregor, 2001; Elliot \& Murayama, 2008; Eum \& Rice, 2011) and between mastery avoidance and academic achievement (Cury et al., 2006; Elliot \& McGregor, 2001; Elliot \& Murayama, 2008; King \& McInerney, 2014). The relation between work avoidance and academic performance is more straightforward; researchers consistently found negative relations (Brdar et al., 2006; Harackiewicz, Barron, Carter, Lehto, \& Elliot, 1997; Harackiewicz et al., 2008; King \& McInerney, 2014). All of these results, however, are based on research among children, adolescents, and college students within traditional education. 


\section{Goal Orientation and Academic Performance in Distance Education}

Within distance education, research on goal orientation associated with academic performance is limited. To our knowledge, the research of Remedios and Richardson (2013) is the only study in which the relationship between goal orientation and academic achievement for adult students in a distance education setting was examined. Remedios and Richardson found a positive relationship between performance approach and examination grades and a negative relationship between mastery avoidance and performance avoidance with examination grades. They did not investigate work avoidance goal orientation.

In the Remedios and Richardson (2013) study, students were enrolled in three specific courses within an educational program at the Open University of the United Kingdom (UKOU). These courses were part of an educational system that was organised into semesters similar to traditional education. However, in this type of distance education, students do not have the opportunity to study fully at their own pace. In contrast, in the present study, students have the opportunity to study at their own pace since the educational system is a modular system in which students have 14 months from the moment they enrol to finish a course. They determine their pace themselves. Therefore, the present study was designed to investigate the relationship between goal orientation (including work avoidance) and academic performance in adult distance education within a self-paced modular system.

\section{Present Study}

The present study was designed to increase knowledge about the relationship between goal orientation and academic performance for adult distance learners. The research question that was investigated was: "What is the predictive value of goal orientation on academic performance for adult distance learners?” To study this, a 2 x 2 framework, as first described by Elliot and McGregor (2001), was used and was supplemented with the work avoidance goal orientation (Harackiewicz et al., 2008). Participants in the present study are expected to be highly mastery oriented compared to children and adolescents, as adult distance learners actively choose to enrol in a study while children and adolescents are required by law. Furthermore, since students are mostly working from their own homes, competitiveness against other students is expected not to play a big roll (Sachs, 2001). Even though these differences between populations in goal orientation were expected, it was hypothesised that: (1) mastery approach as well as mastery avoidance are not significantly related to academic performance, (2) performance approach is positively related to academic performance, and (3) performance avoidance and work avoidance are negatively related to academic performance.

\section{Methods}

\section{Design}

This study is part of the ALOUD study, a large observational longitudinal study in which a broad range of biological and psychological determinants of learning performance within adult distance education was investigated (for more detailed information regarding the ALOUD study, see Neroni, Gijselaers, Kirschner, \& de Groot, 2015). In this study, baseline measurements of goal orientation and work avoidance were used. These data were linked to academic performance data after 14 months. 
The ALOUD study was approved by the Ethics Committee of the Open University of the Netherlands (OUNL).

\section{Setting}

All data were collected from students participating in adult distance education at the OUNL. The OUNL has an open admission policy (i.e., no prior education is required) and the only requirement is a minimum age of 18 years. The OUNL has seven educational bachelor and master programs: Law, Management Science, Computer Science, Environmental Science, Cultural Science, Learning Sciences, and Psychology. Up until September 2014, students could enrol in one or more individual courses at once, or in a full-length degree program, and could choose from nearly 300 courses. A course consisted of one or more study modules, each corresponding to 4.3 European Credits (ECs; i.e., 120 hours of studying). Students could enrol in a course at any moment and were able to choose their own study pace during a period of 14 months.

\section{Participants}

Between August $6^{\text {th }}, 2012$ and August $5^{\text {th }}$, 2013, all newly registered students at the OUNL were approached to participate in the ALOUD study. In total, 4,945 students were approached, of which 2,842 (57.5\%) agreed to participate in the study. Eventually, 2,040 (41.3\%) fully completed the questionnaire.

Exclusion criteria were: (a) not attempting an exam within 14 months $(n=894)$, as academic performance could not be determined without exam information; (b) no data available on academic performance $(n=13)$; and (c) courses exclusively with a pass/fail exam $(n=5)$. Only courses that were finished with a traditional exam where a grade was given were included in the current dataset in order to calculate performance scores. Analyses were conducted on the remaining 1,128 participants (708 females, 420 males, $M_{a g e}=35.4$ years, age range: $18-75$ years).

\section{Procedure}

Students received an automatic email invitation to participate in the ALOUD study 14-21 days after their registration at the OUNL. After reading the introduction and ticking a box to indicate informed consent, participants filled out an online questionnaire (see Neroni, Gijselaers, Kirschner, \& de Groot, 2015). Total time investment of the baseline measurement was approximately 45-60 minutes. Participants had the possibility to pause and/or leave the questionnaire and return to it at any time.

Non-respondents and non-completers received an email reminder after two weeks and were followed up with a final email reminder one week later. Finally, individuals who had not completed the questionnaire or did not respond to the mail were approached by phone one week after the last e-mail. In total, recruited students had 9 weeks to complete the questionnaire. To increase participation in the ALOUD study gift coupons of 20 euro with a winning chance of $5 \%$ were allotted as an incentive.

The exam database of the OUNL was used for data extraction on examination grades of the participants.

\section{Measurements}

Questionnaires which were originally in English were translated from English into Dutch by a native Dutch speaker. To ensure the content validity, the items were translated back into English by a bilingual English/Dutch speaking person and adjustments were made where necessary. In addition, 
those aspects of the tests which did not apply with the current setting (i.e., adult distance education) were replaced by the most relevant analogous alternative. For example, in the current questionnaires, this class was replaced by a course.

Goal orientation. Goal orientation was measured with the Achievement Goal Questionnaire (AGQ; Elliot \& McGregor, 2001), which has four subscales. The subscales, consisting of three items each, are: (1) mastery approach (e.g., I want to learn as much as possible from a course), (2) mastery avoidance (e.g., I worry that I may not learn all that I possibly could in a course), (3) performance approach (e.g., It is important for me to do better than other students), and (4) performance avoidance (e.g., I just want to avoid doing poorly in a course). Work avoidance was measured using the 3-item work avoidance subscale of a questionnaire developed by Harackiewicz et al. (2008; e.g., I don't want to work hard in a course). All items had to be answered on a 7-point scale, ranging from totally disagree (1) to totally agree (7). Elliot and McGregor (2001) reported Cronbach's alphas ranging from .87 to .89 for mastery approach, from .84 to .89 for mastery avoidance, from .92 to .96 for performance approach, and from .82 to .83 for performance avoidance. Harackiewicz and colleagues (2008) reported a Cronbach's alpha of .90 for work avoidance.

Academic performance. Academic performance was conceptualised using all the examination grades the students obtained for the courses followed within 14 months after their registration at the OUNL. This data was extracted from the exam database of the OUNL. Students were free to choose the number of courses they wanted to follow within this 14 month period. Therefore, academic performance was calculated per course nested within students.

Covariates. In literature, age (Lee \& Choi, 2011), gender (Duckworth \& Seligman, 2006), and intended study hours (Bernt \& Bugbee, 1993) were found to be related to academic performance. For this reason, these variables were investigated as possible confounders. These variables were measured by the online questionnaire participants completed. Additionally, as it is known that academic performance differs for students at different faculties, faculty was investigated as possible confounder. Furthermore, the number of study modules within a course was investigated as possible confounder, as the workload per course differed (i.e., some courses only consisted of one module corresponding to 4.3 European Credits, while other courses consisted of two or more modules). Faculty and number of modules per course were gathered from the exam database of the OUNL.

\section{Statistical Analyses}

All analyses were conducted using SPSS 22.0.o (Chicago, IL, USA). First, descriptive statistics were reported for all measured variables. Second, although this was outside the scope of present study, ttests and a chi-square test were conducted to investigate group differences between participants included and excluded from the main analyses, to check for potential sampling bias. Third, several non-parametric tests (i.e., Spearman rank order correlation, Mann-Whitney U tests, and KruskalWallis tests) were performed to investigate which variables were possible confounders (i.e., variables that threaten the internal validity of the study). Variables which were significantly related to both academic performance and goal orientation with an effect size of $\geq .10$ were included in the main analysis (i.e., the mixed model regression analysis) as covariates (as effect sizes of <.10 are indicated as trivial; Cohen, 1992). If a variable was not related to either goal orientation or academic performance, it could not distort the identified effect size, and therefore, the variable was not included as a covariate. Fourth, to investigate the relationship between goal orientation and academic performance, a mixed model regression analysis was conducted. Students could follow a variable 
number of courses during the study period of 14 months. Therefore, the analysis was not run with a composite score of all examination grades but mixed model regression was run for individual course grades while accounting for the correlation of exam grades for different courses $(N=2544)$ nested within students $(N=1128)$. The following models built to the final model: (1) Model o: Only a fixed intercept without hierarchical structure; (2) Model 1: Covariates as fixed variables were entered; (3) Model 2: Predictors as fixed variables were entered; (4) Model 3: Random intercepts were added; and (5) Model 4: Random slopes were added. Building to a next model was only performed if the model was significantly better than the previous model. If the model did not improve significantly, the final model was reached. For each model, this was tested with a chi-square model comparison.

\section{Results}

\section{Descriptive Statistics}

Overall, students seemed to report highest on mastery approach goal orientation $(M=5.55, S D=.92)$ and lowest on work avoidance $(M=2.70, S D=1.17)$. An overview of the descriptive statistics of all variables, as well as internal consistency of the goal orientation scales, is given in Table 1. As Cronbach's alpha for performance avoidance goal orientation was rather low (i.e., $\alpha=.55$ ), inter-item correlations, as well as item-total correlations, were taken into account to assess the reliability of the subscale. Inter-item correlations ranged from .22 to .35, and item-total correlations ranged from .32 to .42. As the optimal inter-item correlation is between .20 and .40 (Briggs \& Cheek, 1986), and the item-total correlations should best be above .30 (Field, 2009), it was justified to include the subscale of performance avoidance in the main analyses.

Table 1

Participant Characteristics

\begin{tabular}{lrrrr}
\hline Variables & $M$ & $S D$ & Min - max & $\alpha$ \\
\hline Mastery approach & 5.55 & .92 & $1.67-7.00$ & .75 \\
Mastery avoidance & 3.44 & 1.36 & $1.00-7.00$ & .78 \\
Performance approach & 2.90 & 1.48 & $1.00-7.00$ & .88 \\
Performance avoidance & 3.76 & 1.18 & $1.00-7.00$ & .55 \\
Work avoidance & 2.70 & 1.17 & $1.00-6.33$ & .81 \\
Age (years) & 35.36 & 11.20 & $18-75$ & \\
Intended study hours (per week) & 13.38 & 7.62 & $1-60$ & \\
Academic performance a & 6.31 & 1.71 & $1-10$ & \\
\hline & Count & $\%$ of total & & \\
\hline Sex & & & & \\
$\quad$ Male & 420 & 37.2 & & \\
$\quad$ Female & 708 & 62.8 & & \\
Number of modules per course & & & & \\
$\quad$ One & 1548 & 60.8 & & \\
\hline
\end{tabular}




\begin{tabular}{lrr}
\hline More than one & 996 & 39.2 \\
Faculty & & \\
Learning sciences & 131 & 5.1 \\
Environmental sciences & 58 & 2.3 \\
Law & 651 & 25.6 \\
Management sciences & 201 & 7.9 \\
Psychology & 963 & 37.9 \\
Computer sciences & 285 & 11.2 \\
Cultural sciences & 255 & 10.0
\end{tabular}

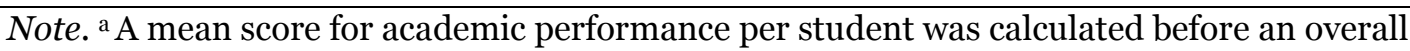
mean score was calculated, b At course level, $N=2544$.

\section{Included vs. Excluded Participants}

Included $(n=1128)$ and excluded $(n=912)$ participants were compared to investigate group differences on gender, age, intended study hours per week, and goal orientation scores. A chi-square test showed that there was no group difference for gender, $\chi^{2}(1, N=2040)=1.07, p=.30$. An independent samples t-test showed a significant difference between included $\left(M_{\text {age }}=35.36, S D=\right.$ 11.20) and excluded $\left(M_{\text {age }}=38.34, S D=10.87\right)$ participants for age, $t(2038)=6.06, p<.001$. Also, included $(M=13.38$ hours, $S D=7.62)$ participants intended to study more hours per week than excluded $(M=10.80$ hours, $S D=6.80)$ participants, $t(2018.07)=-8.09, p<.001$. Furthermore, included participants scored significantly higher on performance approach goal orientation, $t(2038)=-1.99, p=.05\left(M_{\text {included }}=2.90, S D=1.48 ; M_{\text {excluded }}=2.77, S D=1.45\right)$, and on performance avoidance goal orientation $t(2038)=-3.24, p=.001\left(M_{\text {included }}=3.76, S D=1.18 ; M_{\text {excluded }}=3.59, S D=\right.$ 1.20), than excluded participants. There were no group differences for mastery approach, $t(2038)=1.24, p=.22$, mastery avoidance, $t(2038)=-1.14, p=.26$, and work avoidance, $t(2038)=0.70, p=.48$.

\section{Possible Confounders}

Possible confounders and academic performance. A Kolmogorov-Smirnov test was performed to test for normality. Academic performance significantly deviated from normality, $D(2544)=.15, p<.001$. Therefore, non-parametric tests were performed to test whether possible confounders were related to academic performance. Spearman rank order correlation showed a positive correlation between age and academic performance, $r_{\mathrm{s}}=.13, p<.001$. Intended study hours per week and academic performance were negatively correlated, $r_{\mathrm{s}}=-.05, p=.008$, but the effect size was negligible. Furthermore, females $(M d n=7.00)$ scored significantly higher than males $(M d n=7.00)$ on academic performance, $U=722,642.50, p=.001, r=-.06$, but the effect size was negligible. Also, academic performance was greater for courses consisting of more than one module $(M d n=7.00)$ than for courses consisting of only one module ( $M d n=7.00), U=707,091.00, p<.001$, $r=-.07$, with a negligible effect size. A Kruskal-Wallis test indicated a statistically significant difference between academic performance by different faculties, $H(6)=57.88, p<.001$. Six MannWhitney $\mathrm{U}$ tests were performed as post hoc comparisons using the Bonferroni adjusted alpha levels of .008 (i.e., 0.05/6). Psychology courses $(M d n=7.00)$ scored significantly lower on academic performance than Management Sciences courses ( $M d n=7.00$ ), $U=80,191.00, p<.001, r=-.11$ and Learning Sciences courses $(M d n=7.00), U=45,892.00, p<.001, r=-.16$. 
Possible confounders and goal orientation. A Kolmogorov-Smirnov test showed that all goal orientation scales significantly deviated from normality, $D(1128)$ ranging from .08 to .17, with $p s<$.001. Therefore, non-parametric tests were performed to test whether possible confounders were related to goal orientation. The previous section showed no or trivial effect sizes for the relationships between academic performance and intended study hours per week, gender, and number of modules within a course. For this reason, only age and faculty were analysed in relation to goal orientation as possible confounders. Spearman rank order correlation showed a significant negative correlation between age and mastery avoidance, $r_{\mathrm{s}}=-.19, p<.001$, performance approach, $r_{\mathrm{s}}=-.24, p<.001$, performance avoidance, $r_{\mathrm{s}}=-.25, p<.001$, and work avoidance, $r_{\mathrm{s}}=-.19, p<.001$. Five KruskalWallis tests showed differences between faculties for all goal orientation scales, with $H(6)$ ranging from 17.80 to 62.86 , with $p s<.01$. The main analysis, therefore, included age and faculty as covariates.

\section{Goal Orientation Predicting Academic Performance}

A linear mixed model regression analysis was performed to investigate the predictive value of goal orientation on academic performance. A model including all predictors with intercepts as well as slopes varying across participants (i.e., Model 4) was the best fitting model and a significant improvement compared to Model o to 3 (see Table 2). Work avoidance showed to be the strongest and a negative predictor of academic performance, $F(1,728.85)=16.64, p<.001$, indicating that the more students wanted to gain high grades with as little effort as possible, the lower their exam grades were. Also, performance avoidance was found to be a significant negative predictor of academic performance, $F(1,860.37)=4.52, p=.03$, indicating that those students who wanted to prevent obtaining a lower score than other students (i.e., avoiding looking bad), in fact had lower exam grades. Performance approach was a significant positive predictor of academic performance, $F(1,746.48)=5.13, p=.02$. In other words, increment in performance approach was associated with higher exam grades. Mastery approach $(F(1,294.00)=0.09, p=.76)$ as well as mastery avoidance $(F(1,896.73)=0.72, p=.40)$ were no significant predictors of academic performance.

Table 2

Fixed Effects for Models of the Predictors of Students' Grades

\begin{tabular}{lccc}
\hline & Estimate & SE & $95 \%$ CI \\
\hline $\begin{array}{l}\text { Model } o\left(\chi^{2}=10,028.25 ; d f=2\right) \\
\text { Intercept }\end{array}$ & $6.58^{* * *}$ & 0.03 & {$[6.52,6.65]$} \\
& & & \\
Model 1 $\left(\chi^{2}=9,936.87 ; d f=9\right)$ & & & \\
Intercept & $5.91^{* * * *}$ & 0.13 & {$[5.66,6.16]$} \\
Age & $0.02^{* * *}$ & 0.00 & {$[0.01,0.03]$} \\
Faculty (Psychology as reference) & & & \\
$\quad$ Educational sciences & $0.69^{* * *}$ & 0.16 & {$[0.38,1.01]$} \\
$\quad$ Environmental sciences & $-0.47^{*}$ & 0.23 & {$[-0.93,-0.02]$} \\
$\quad$ Law & $-0.24^{* * *}$ & 0.09 & {$[-0.41,-0.07]$} \\
$\quad$ Management sciences & $0.42^{* * *}$ & 0.13 & {$[0.16,0.68]$} \\
\hline
\end{tabular}


Computer sciences
Cultural sciences
Model $2\left(\chi^{2}=9,896.68 ; d f=14\right)$
Intercept

Intercept

Age

Faculty

Educational sciences

Environmental sciences

Law

Management sciences

Computer sciences

Cultural sciences

Goal orientation

Mastery approach

Mastery avoidance

Performance approach

Performance avoidance

Work avoidance

Model $3\left(\chi^{2}=9,378.88 ; d f=15\right)$

Intercept

Age

Faculty

Educational sciences

Environmental sciences

Law

Management sciences

Computer sciences

Cultural sciences

Goal orientation

Mastery approach

Mastery avoidance

Performance approach

Performance avoidance

Work avoidance
$0.26^{*}$

0.04

$6.71^{* * * *}$

0.31

0.00

0.16

0.23

0.09

0.13

0.12

0.12

0.04

0.03

0.02

0.03

0.03

$-0.11^{* * *}$
$6.86^{* * *}$
$0.01^{*}$

$0.72^{* * *}$

$-0.45$

$-0.26^{*}$

$0.69^{* * * *}$

$0.40^{*}$

0.28

$$
-0.03
$$

$-0.04$

$0.08^{*}$

$-0.10^{*}$

$-0.19^{* * * *}$
0.44

0.00

0.18

0.28

0.12

0.16

0.17

0.16

0.06

0.04

0.04

0.05

0.05

0.42

0.00
$[6.10,7.32]$

[0.01, 0.02]

$[-0.20,0.28]$

[0.40, 1.02]

[-0.96, -0.06]

[-0.39, -0.05]

[0.21, 0.72]

$[0.03,0.48]$

[-0.22, 0.26]

[-0.06, 0.10]

[-0.12, -0.01]

[0.01, 0.11]

$[-0.18,-0.04]$

[-0.17, -0.05]

[6.01, 7.72]

[0.00, 0.02]

$[0.37,1.06]$

[-1.00, 0.09]

[-0.49, -0.03]

[0.38, 1.00]

$[0.07,0.72]$

[-0.04, 0.6o]

Model $4\left(\chi^{2}=9,364.23 ; d f=20\right)$

Intercept

$6.8 \mathrm{o}^{* * * *}$

[5.98, 7.62]

Age

$0.01^{*}$

$[0.00,0.02]$ 


\begin{tabular}{lccc}
\hline Faculty & & & \\
Educational sciences & $0.69^{* * * *}$ & 0.18 & {$[0.34,1.03]$} \\
Environmental sciences & -0.49 & 0.27 & {$[-1.02,0.05]$} \\
Law & $-0.25^{*}$ & 0.12 & {$[-0.47,-0.02]$} \\
Management sciences & $0.71^{* * *}$ & 0.16 & {$[0.40,1.02]$} \\
Computer sciences & $0.41^{*}$ & 0.16 & {$[0.09,0.73]$} \\
Cultural sciences & 0.29 & 0.16 & {$[-0.01,0.60]$} \\
Goal orientation & & & \\
Mastery approach & -0.02 & 0.05 & {$[-0.12,0.09]$} \\
Mastery avoidance & -0.03 & 0.04 & {$[-0.11,0.04]$} \\
Performance approach & $0.08^{*}$ & 0.04 & {$[0.01,0.15]$} \\
Performance avoidance & $-0.10^{*}$ & 0.05 & {$[-0.20,-0.01]$} \\
Work avoidance & $-0.19^{* * *}$ & 0.05 & {$[-0.28,-0.10]$} \\
\hline
\end{tabular}

Note. $\mathrm{SE}=$ Standard Error; $\mathrm{CI}=$ Confidence Interval, ${ }^{*} p<.05 ;{ }^{* *} p<.01 ;{ }^{* * *} p<.001$.

\section{Discussion}

The aim of the current study was to investigate the predictive value of goal orientation on academic performance in adult distance learners. Results of 1,128 students participating in adult distance education at the OUNL revealed that mastery approach, as well as mastery avoidance, were not significantly related to academic performance. Performance approach was a positive predictor of academic performance, whereas performance avoidance and work avoidance were negative predictors. These results confirmed the hypotheses of the present study.

For college students in traditional education, past research also failed to find a relationship between mastery approach and academic outcomes as well as mastery avoidance and academic outcomes (Elliot \& McGregor, 2001; Cury et al., 2006). One explanation for not finding these relationships is that students who are highly mastery oriented study primarily to gain knowledge. This may be an indication that obtaining high grades might be less important to them. They might not push themselves that hard to finish their courses with high grades as much as performance approach oriented students do. In other words: highly mastery oriented students might obtain their personal goal (i.e., gaining knowledge) while this is not expressed in their academic performance (i.e., their grades). To find out if this is the case, future research should also investigate students' subjective learning performance next to academic performance in terms of grades.

Although adult distance learners seem to score much lower on performance approach and performance avoidance than the college students studied by Elliot and McGregor (2001), the directions of the relationship between these orientations and academic performance remain the same. Hence, even though performance approach and performance avoidance may not be as important to adult learners as it is to young learners (Sachs, 2001), focusing on doing better than others is still beneficial for earning high grades, while focusing on avoiding doing worse than others remains a maladaptive educational strategy. 
This study shows that goal orientation is a significant predictor of academic performance during a period of 14 months of studying. The relationship between goal orientation and academic performance in adult distance education has hardly been studied before, with the exception of the research of Remedios and Richardson (2013). The present study partly replicates their findings, as they also found performance approach to be a positive predictor and performance avoidance to be a negative predictor of exam grades. Their negative prediction of mastery avoidance, however, was not found in the present study. The strength of the present study compared to theirs is that in the present study all followed courses within a timeframe of 14 months were taken into account instead of only one course. Also, the research here deals with a modular model of distance education, which is more the "norm" than the more regulated setting studied by them. Furthermore, Remedios and Richardson (2013) did not investigate work avoidance in their research.

This is the first study that investigated work avoidance in relation to academic performance in adult distance education. A big difference between younger and adult students is that adult students generally voluntarily choose to study, while for younger students school is compulsory and, thus, is experienced as such. This might explain why students in the present study scored relatively low on work avoidance compared to students in traditional education research (Harackiewicz et al., 1997; Harackiewicz et al., 2008). Adult students might also be work avoidant for different reasons than younger students. For example, adult distance students often have busy lives (e.g., they have a fulltime job, a family, and/or a more social life during the week). As a result, finding time to study might be difficult for them. Participants in the present study and in the study of Harackiewicz and colleagues (2008) may have interpreted the same items in a different way because of the different mind-set they have. Despite these differences in work avoidance scores, the negative relationship with academic performance remained the same.

Included and excluded participants were compared to see whether the sample of present study was biased. These groups were compared for gender, age, intended study hours per week, and goal orientation scores. Included students were significantly older and intended to study more hours per week then excluded students. Furthermore, included participants scored higher on performance approach as well as performance avoidance goal orientation. Excluded students did not attempt an exam within the 14 months period. As the reasons for not attempting an exam are not known, it remains speculation how the difference in performance approach and performance avoidance for these groups could be explained. For instance, some students might not have aimed for finishing the course and taking the exam in the first place, but only started the course to gain knowledge. It is plausible that these students would have a different goal orientation than students who did aim for finishing the course, but along the way, found out it was not feasible. Future research should indicate whether the differences in goal orientation scores could be clarified by looking into the reasons for students not attempting an exam.

To summarise, in the present study, a significant association was found between performance approach, performance avoidance, and work avoidance on the one hand and academic performance on the other hand. This study was a first step to examine the relationship between goal orientation and academic performance within adult distance education. It contributes to goal orientation as well as distance education literature in several important ways. First, to our knowledge, this was the first study in which goal orientation, including work avoidance, was examined within adult distance education. Second, it was a large scale study, which decreases the high risk of a type-I error. Third, the 
modular system in this research, in which students can study in their own time and at their own pace, makes this research unique compared to the research of Remedios and Richardson (2013).

Nevertheless, this study had some limitations, and these considerations should be taken into account. First, the significant estimates that were found were rather small, suggesting that practical relevance is lacking. However, looking at work avoidance, for instance, a one point increase in work avoidance score resulted in a 0.19 decrease in academic performance. This could make a difference in a grades score of 1.15 (on a range of 1 to 10) between people with a low and a high work avoidance orientation. Therefore, these results should not be neglected. Second, it must be mentioned that results are exclusively based on observational research, so no conclusions of causality can be drawn from these results. Furthermore, academic performance in the present study was measured within a time frame of 14 months. For future research, it would be valuable to extend this time frame and to follow students throughout their study career at the OUNL. Finally, goal orientation was measured as a trait, i.e., generally for all enrolled courses. It is possible that students adopt different goal orientations for different courses. Future research could reveal whether the relationship with academic performance would remain the same if goal orientation was measured at course level.

Several important implications could be drawn from this study. Knowing that performance approach is beneficial and that performance avoidance as well as work avoidance are detrimental for academic performance gives educators the opportunity to anticipate on this in their courses. It also gives educators the opportunity to monitor and give extra attention to students who are at risk for low performance. Furthermore, to increase study success or to lower study dropout, these results offer opportunities for future research to develop interventions that stimulate the development of a performance approach orientation, and to demotivate development of a performance avoidance or a work avoidance orientation. 


\section{References}

Abd-El-Fattah, S. M., \& Patrick, R. R. (2011). The relationship among achievement motivation orientations, achievement goals, and academic achievement and interest: A multiple mediation analysis. Australian Journal of Educational and Developmental Psychology, 11, $91-110$.

Anderman, E. M., \& Midgley, C. (1997). Changes in achievement goal orientations, perceived academic competence, and grades across the transition to middle-level schools. Contemporary Educational Psychology, 22, 269-298. https://doi.org/10.1006/ceps.1996.0926

Berge, Z. L., \& Huang, Y.-P. (2004). A Model for sustainable student retention: A Holistic perspective on the student dropout problem with special attention to e-learning. Deosnews, 13(5), 26.

Bernt, F. M., \& Bugbee, A. C. (1993). Study practices and attitudes related to academic success in a distance learning programme. Distance Education, 14, 97-112. https://doi.org/10.1080/0158791930140108

Brdar, I., Rijavec, M., \& Loncaric, D. (2006). Goal orientations, coping with school failure and school achievement. European Journal of Psychology of Education, 21, 53-70. https://doi.org/10.1007/BFo3173569

Briggs, S. R., \& Cheek, J. M. (1986). The role of factor analysis in the development and evaluatbn of personality scales. Journal of Personality, 54, 106-148. https://doi.org/10.1111/j.14676494.1986.tboo391.x

Butler, R. (2008). Ego-involving and frame of reference effects of tracking on elementary school students' motivational orientations and help seeking in math class. Social Psychology of Education, 11, 5-23. https://doi.org/10.1007/s11218-007-9032-0

Cellar, D. F., Stuhlmacher, A. F., Young, S. K., Fisher, D. M., Adair, C. K., Haynes, S., ... Riester, D. (2011). Trait goal orientation, self-regulation, and performance: A meta-analysis. Journal of Business and Psychology, 26, 467-483. https://doi.org/10.1007/s10869-010-9201-6

Chen, W. W. (2015). The relations between perceived parenting styles and academic achievement in Hong Kong: The mediating role of students' goal orientations. Learning and Individual Differences, 37, 48-54. https://doi.org/10.1016/j.lindif.2014.11.021

Cohen, S. (1992). A power primer. Psychological Bulletin, 112, 155-159. https://doi.org/10.1037/0033-2909.112.1.155

Cury, F., Elliot, A. J., Da Fonseca, D., \& Moller, A. C. (2006). The social-cognitive model of achievement motivation and the 2 x 2 achievement goal framework. Journal of Personality and Social Psychology, 9o, 666-679. https://doi.org/10.1037/0022-3514.90.4.666

DeShon, R. P., \& Gillespie, J. Z. (2005). A motivated action theory account of goal orientation. The Journal of Applied Psychology, 90, 1096-1127. https://doi.org/10.1037/00219010.90.6.1096 
Diseth, Å. (2011). Self-efficacy, goal orientations and learning strategies as mediators between preceding and subsequent academic achievement. Learning and Individual Differences, 21, 191-195. https://doi.org/10.1016/j.lindif.2011.01.003

Duckworth, A. L., \& Seligman, M. E. P. (2006). Self-discipline gives girls the edge: Gender in selfdiscipline, grades, and achievement test scores. Journal of Educational Psychology, 98, 198208. https://doi.org/10.1037/0022-0663.98.1.198

Dweck, C. S. (1986). Motivational processes affecting learning. American Psychologist, 41, 10401048.https://doi.org/10.1037/0003-066X.41.10.1040

Elliot, A. J., \& Church, M. A. (1997). A hierarchical model of approach and avoidance achievement motivation. Journal of Personality and Social Psychology, 72, 218-232. https://doi.org/10.1037/0022-3514.72.1.218

Elliot, A. J., \& Harackiewicz, J. M. (1996). Approach and avoidance achievement goals and intrinsic motivation: A mediational analysis. Journal of Personality and Social Psychology, 70, 461475. https://doi.org/10.1037/0022-3514.70.3.461

Elliot, A. J., \& McGregor, H. A. (2001). A $2 \times 2$ achievement goal framework. Journal of Personality and Social Psychology, 8o, 501-519. https://doi.org/10.1037/0022-3514.80.3.501

Elliot, A. J., \& Murayama, K. (2008). On the measurement of achievement goals: Critique, illustration, and application. Journal of Educational Psychology, 100, 613-628. https://doi.org/10.1037/0022-0663.100.3.613

Elliot, A. J., Murayama, K., \& Pekrun, R. (2011). A $3 \times 2$ achievement goal model. Journal of Educational Psychology, 103, 632-648. https://doi.org/10.1037/ao023952

Eum, K., \& Rice, K. G. (2011). Test anxiety, perfectionism, goal orientation, and academic performance. Anxiety, Stress, and Coping, 24, 167-178. https://doi.org/10.1080/10615806.2010.488723

Eurostat. (2016). Lifelong learning statistics. Retrieved from http://ec.europa.eu/

Field, A. (2009). Discovering statistics using SPSS. London: SAGE.

Greene, B. A., Miller, R. B., Crowson, H. M., Duke, B. L., \& Akey, K. L. (2004). Predicting high school students' cognitive engagement and achievement: Contributions of classroom perceptions and motivation. Contemporary Educational Psychology, 29, 462482.https://doi.org/10.1016/j.cedpsych.2004.01.006

Harackiewicz, J. M., Barron, K. E., Carter, S. M., Lehto, A. T., \& Elliot, A. J. (1997). Predictors and consequences of achievement goals in the college classroom: Maintaining interest and making the grade. Journal of Personality and Social Psychology, 73, 1284-1295. https://doi.org/10.1037/oo22-3514.73.6.1284

Harackiewicz, J. M., Durik, A. M., Barron, K. E., Linnenbrink-Garcia, L., \& Tauer, J. M. (2008). The role of achievement goals in the development of interest: Reciprocal relations between 
achievement goals, interest, and performance. Journal of Educational Psychology, 100, 105122. https://doi.org/10.1037/0022-0663.100.1.105

Huang, C. (2012). Discriminant and criterion-related validity of achievement goals in predicting academic achievement: A meta-analysis. Journal of Educational Psychology, 104, 48-73. https://doi.org/10.1037/aoo26223

King, R. B., \& McInerney, D. M. (2014). The work avoidance goal construct: Examining its structure, antecedents, and consequences. Contemporary Educational Psychology, 39, 42-58. https://doi.org/10.1016/j.cedpsych.2013.12.002

Lee, Y., \& Choi, J. (2011). A review of online course dropout research: Implications for practice and future research. Educational Technology Research and Development, 59, 593-618. https://doi.org/10.1007/s11423-010-9177-y

Nagy, B., Farmer, J. D., Bui, Q. M., \& Trancik, J. E. (2013). Statistical basis for predicting technological progress. PLoS ONE, 8(2), e52669. https://doi.org/10.1371/journal.pone.0052669

Neroni, J., Gijselaers, H. J. M., Kirschner, P. A., \& de Groot, R. H. M. (2015). The adult learning open university determinants (ALOUD) study: Biological and psychological factors associated with learning performance in adult distance education. British Journal of Educational Technology, 46, 953-96o. https://doi.org/10.1111/bjet.12288

Nicholls, J. G. (1984). Achievement motivation: Conceptions of ability, subjective experience, task choice, and performance. Psychological Review, 91, 328-346. https://doi.org/10.1037/0033295X.91.3.328

Payne, S. C., Youngcourt, S. S., \& Beaubien, J. M. (2007). A meta-analytic examination of the goal orientation nomological net. The Journal of Applied Psychology, 92, 128-150. https://doi.org/10.1037/0021-9010.92.1.128

Pekrun, R., Elliot, A. J., \& Maier, M. A. (2009). Achievement goals and achievement emotions: Testing a model of their joint relations with academic performance. Journal of Educational Psychology, 101, 115-135. https://doi.org/10.1037/ao013383

Remedios, R., \& Richardson, J. T. E. (2013). Achievement goals in adult learners: Evidence from distance education. British Journal of Educational Psychology, 83, 664-685. https://doi.org/10.1111/bjep.12001

Sachs, J. (2001). A path model for adult learner feedback. Educational Psychology, 21, 267-275. https://doi.org/10.1080/01443410120065478

Schlosser, L. A., \& Simonson, M. (2010). Distance education: Definition and glossary of terms. Distance education: Definition and glossary terms (3th ed.). Charlotte, North Carolina: Information Age Publishing.

Steinmayr, R., Bipp, T., \& Spinath, B. (2011). Goal orientations predict academic performance beyond 
intelligence and personality. Learning and Individual Differences, 21, 196-200.

https://doi.org/10.1016/j.lindif.2010.11.026

Steinmayr, R., \& Spinath, B. (2009). The importance of motivation as a predictor of school achievement. Learning and Individual Differences, 19, 80-90.

https://doi.org/10.1016/j.lindif.2008.05.004

Yukselturk, E., Ozekes, S., \& Türel, Y. K. (2014). Predicting dropout student : An application of data mining methods in an online education program. European Journal of Open, Distance and $E$ Learning, 17, 118-133. https://doi.org/10.2478/eurodl-2014-0oo8

\section{Athabasca}

University

(C) $(1)$ 